\title{
O ESTUDO DE ORGANIZAÇ̃̃ES CULTURAIS: CONSIDERANDO OUTRAS POSSIBILIDADES
}

\author{
CONSIDERING OTHER POSSIBILITIES IN THE STUDY OF CULTURAL ORGANIZATIONS
}

\section{Adalto Aires Parada}

adalto.parada@hotmail.com

Universidade Federal de Santa Catarina (UFSC), Florianópolis/SC, BRASIL

\section{Eloise Helena Livramento Dellagnelo}

eloise.livramento@ufsc.br

Universidade Federal de Santa Catarina (UFSC), Florianópolis/SC, BRASIL

\section{Resumo}

O objetivo deste ensaio é apresentar uma proposta de análise organizacional que considere outras realidades, não só econômicas, mas que inclua organizações isonômicas e fenonômicas. Para tal, se apoia na teoria do Paradigma Paraeconômico de Guerreiro Ramos (1981) e na delimitação dos sistemas sociais, considerando a lei dos requisitos adequados e as características das dimensões de tecnologia, tamanho, espaço e tempo. A sugestão é que o quadro proposto sirva como um instrumento heurístico e que permita o raciocínio acerca dessas outras organizações, descortinando as suas possibilidades e o seu conhecimento. A expectativa é a de suscitar a necessidade e despertar o interesse pelo desenvolvimento de uma teoria substantiva da administração, que abarque a entrada de todas as formas possíveis de organizações, não designando princípios formalizados de comportamentos, apoiada em novos fundamentos epistemológicos, como a abordagem substantiva da economia.

Palavras-chave: Organizações culturais. Paradigma paraeconômico. Lei dos requisitos adequados.

\section{Abstract}

The aim of this essay is to present a proposal for organizational analysis that takes into consideration other realities, not only economic, but including isonomic and fenonomic organizations. The essay is based on the Para-economic Paradigm developed by Guerreiro Ramos (1981) and on the delimitation of the social systems, considering the law of requisite adequacy, and the characteristics of the dimensions technology, size, space and time. It is suggested that this proposal works as a heuristic instrument that allows reflecting about these other organizations, opening up possibilities and knowledge. The author seeks to promote the interest for the development of a substantive theory of administration, which includes all possible forms of organizations, without designating formalized principles of behaviors and based on new epistemological foundations such as those used for the substantive approach of economy.

Keywords: Cultural organizations. Para-economic paradigma. Law of requisite adequacy. 


\section{Introdução}

O setor artístico envolve um amplo leque de diferentes tipos de práticas, pode ser um pintor, um músico solista ou ainda um membro de uma companhia de teatro, todos dentro de diferentes áreas profissionais, tendo suas próprias histórias para contar, necessitando de tipos específicos de consciência, profissionalismo, atenção pública, equipamentos de financiamento e muitos outros recursos. Dentro dessa perspectiva torna-se clara a impossibilidade, ou, no mínimo, de pequeno senso, de se delimitar de maneira generalizada, abrangente, as organizações culturais, tendo em vista que cada uma traz consigo as características relativas ao seu enclave social de atuação ou à mensagem que procura transmitir (BENDIXEN, 2010).

A gestão das artes e cultura se revela como sendo um grande guarda-chuva que abriga uma gama de atividades com uma grande variedade de lógicas e práticas, existindo evidências significantes de que os padrões de organizações são muito variados. Muitos desses padrões decorrem do princípio baseado em formas que seguem as funções, sem a existência e o auxílio de uma teoria articulada (SUMMERTON; KAY; HUTCHINS, 2006).

Frente a essa questão, uma possibilidade para os estudos dessas organizações parece repousar nas teorias suscitadas por Ramos (1981) e Santos (2002) que abordam a necessidade de se buscar outras formas de se conduzir os estudos acerca das organizações, em especial ao se considerar outras realidades, não somente por meio das teorias consagradas, que são utilizadas na análise de organizações formais baseadas no mercado, que buscam a máxima eficiência, com o foco nos fins sem considerar os meios.

Santos (2002), considerando as ciências sociais, destaca o fato de que os pesquisadores, influenciados por uma perspectiva hegemônica, baseada no mercado, parecem ter uma tendência de somente estudarem as organizações que estão alinhadas ao modelo dominante. Essas pesquisas parecem se preocupar somente em demonstrar o que está certo e o que está errado em relação aos modelos dominantes, se trazem ou não resultados sob a sua lógica.

A experiência social no mundo, sob uma perspectiva de totalidade, é muito mais ampla e variada do que a tradição científica ou filosófica ocidental sugere.
As alternativas, experiências, vistas como riquezas sociais, estão sendo desperdiçadas, pois elas não são investigadas adequadamente, criando-se a ideia de que não existem alternativas e que, entre outros aspectos, a história teria chegado ao fim. A tentativa de tornar essas experiências visíveis e evitar o desperdício, bem como de lhes dar credibilidade, não pode ser feita a partir do emprego de uma ciência social como a conhecemos, pois ela esconde ou desacredita as alternativas (SANTOS, 2002).

É necessária a ampliação da consciência coletiva crítica no Brasil, refletindo uma nova forma de se avaliar e compreender os fatos, revelando o imperativo de se ultrapassar o plano de existência bruta, adotandose uma conduta caracterizada como significativa, fundada de alguma forma na percepção dos limites e possibilidades de seu contexto e, sobretudo, orientada para fins que não signifiquem simplesmente uma mera sobrevivência vegetativa (RAMOS, 1965).

Essa consciência crítica permitiria que os estudiosos sociais passassem de uma posição de assimilação literal e passiva de produtos importados para uma posição baseada em uma assimilação crítica, caracterizada por um procedimento metódico denominado de redução sociológica. A redução pressupõe a eliminação de tudo aquilo que pelo seu caráter acessório e secundário perturba o esforço despendido para compreensão e obtenção do aspecto essencial de um dado (RAMOS, 1965).

Conforme Ramos (1965), a redução sociológica é uma atitude metódica que busca descobrir os pressupostos referenciais de natureza histórica dos objetos e os fatos da realidade social, não admitindo a existência, na realidade social, de objetos sem pressupostos. Ela postula uma noção de mundo que considera que os objetos em parte são constituídos pela perspectiva em que estão inseridos.

Implica assumir que a realidade social não é uma aglomeração confusa, um conjunto desconexo de fatos, mas sim que é sistemática, dotada de sentido, já que a sua matéria é a vida humana. Ao postular a noção de mundo, ela considera que a consciência e os objetos estão reciprocamente relacionados, existe tanto uma intencionalidade da consciência como uma referência do objeto em relação a essa consciência, ambos se encontram em uma infinita e complicada trama de referências (RAMOS, 1965). 
Para tal, é preciso efetuar a ampliação do presente, a qual reflete a necessidade de se aproveitar a oportunidade única de se proceder a uma transformação específica referente ao que presente pode oferecer, ou seja, o carpe diem. O que não está sendo visto hoje, esquecido pela ciência, pode significar uma oportunidade única perdida em relação ao futuro, por isso, voltar-se ao presente, a partir de sua ampliação, torna-se relevante (SANTOS, 2002).

Essa perspectiva atenderia em parte à necessidade de se fortalecer a relação entre a ciência e a virtude, com o uso do conhecimento dito ordinário ou vulgar que insiste em não ser reconhecido pelos modelos dominantes, e que pode ser criado e usado tanto para dar sentido as nossas vidas, como para proporcionar o efetivo emprego do conhecimento científico acumulado para enriquecer nossas vidas, num contributo positivo para a felicidade das pessoas (SANTOS, 2002).

Dentro desse contexto, o objetivo deste ensaio é apresentar uma proposta de quadro de análise para o estudo de organizações culturais que considere essas outras realidades, ampliando o presente, apoiada na proposta de Guerreiro Ramos (1981) da delimitação dos sistemas sociais e na lei dos requisitos adequados.

\section{Paradigma Paraeconômico e Lei dos Requisitos Adequados}

O Paradigma Paraeconômico de Guerreiro Ramos (1981) é uma proposta do autor na direção de se superar a unidimensionalização que tem prevalecido na sociedade, em que a economia de mercado passou a ser central na ordenação da vida das pessoas.

Como ponto central, o modelo multidimensional possui a delimitação organizacional, envolvendo a visão de uma sociedade que é composta de diferentes enclaves, com o homem atuando em diferentes atividades substantivas integrativas entre si. $\mathrm{O}$ modelo multidimensional pressupõe que o mercado é um enclave social legítimo e necessário, porém limitado e regulado (RAMOS, 1981).

Como categorias delimitadoras do paradigma paraeconômico, Ramos (1981) apresenta os seguintes enclaves: anomia, horda, economia, isonomias, fenonomias e isolado. A anomia é definida como sendo uma situação de restrição na qual a vida social e pessoal se desvanece, nessa condição os indivíduos vivem nas bordas do sistema social. A horda são as coletividades humanas sem normas, em que falta nos membros o senso de ordem social. A economia se refere a um sistema organizacional altamente ordenado, constituído para a produção de bens e/ou prestação de serviços. A isonomia é uma organização em que seus membros são iguais. A fenonomia é um sistema social que ocorre esporadicamente ou de forma mais ou menos estável, é conduzido por indivíduo ou por um pequeno grupo, prevalecendo o máximo de opção pessoal com uma reduzida subordinação a prescrições operacionais formais. $\mathrm{O}$ isolado é aquele indivíduo que possui extremo compromisso com uma norma que the é particularíssima (HEIDEMANN; SALM, 2009).

A partir da delimitação dos sistemas sociais, Ramos (1981) expõe as características das dimensões de tecnologia, tamanho, cognição, espaço e tempo para cada um dos enclaves, de forma prática, de maneira que estas possam ser utilizadas como um ponto de partida para a análise e o planejamento, sob uma perspectiva heurística.

Em cada um dos enclaves seobservariaa predominância de algumas características dessas dimensões, as quais estariam associadas à consecução dos seus objetivos. Nas organizações isonômicas e fenonômicas, por exemplo, prevaleceriam características relacionadas a aspectos que privilegiariam a participação nas decisões, a proximidade social, a atualização pessoal a partir do convívio, o interesse coletivo em detrimento do individual e proporções de participantes adequadas as suas metas (RAMOS, 1981).

Já nas economias baseadas no mercado, prevaleceriam características funcionais, relacionadas a decisões mais do tipo top-down, com alguma ou nenhuma participação das pessoas nas decisões, grandes proporções ou preocupação em ver o crescimento como algo linear a ser perseguido, sendo caracterizadas pelo emprego de normas, regulamentos e controle nas suas atividades, espaços sócio-afastadores que não privilegiam o contato pessoal, predominando o conhecimento técnico e o tempo serial, linear ou sequencial, sobre outras formas (RAMOS, 1981).

Apesar de serem cinco as dimensões apresentadas por Ramos (1981), nesta proposta optou-se por considerar 
somente as dimensões de tecnologia, tamanho, espaço e tempo, descartando-se a cognição, pois essa dimensão envolve uma complexidade que justificaria um trabalho único a seu respeito, tendo em vista o que até então já foi produzido nas diferentes ciências, uma vez que envolve a sociologia do saber, conforme apontado por Gurvitch (1969).

\section{Dimensões da Lei dos Requisitos Adequados}

\section{a. Tecnologia}

A tecnologia representa uma parte essencial da estrutura de apoio de qualquer sistema social, existindo como uma série de conjuntos e combinações possíveis de instrumentos que possibilitam a consecução das diferentes tarefas envolvidas no dia a dia das organizações, constituindo parte notória do mundo contemporâneo (RAMOS, 1981; CUPANI, 2013).

A tecnologia é uma realidade polifacetada, que não se refere somente a objetos e seus conjuntos, mas também diz respeito a sistemas, processos, modos de proceder, assim como a uma mentalidade cujo conjunto carrega consigo certa ambiguidade, resultado de uma valoração positiva ou negativa para seus efeitos (CUPANI, 2013).

Atualmente o termo tecnologia é um atributo essencial do pensamento funcional e unidimensional, ou seja, do pensamento na fase da planificação, em que se descobre que a essência da tecnologia não é tecnológica, mas sim resultado da ascensão de uma mentalidade humana totalmente técnica, incompatível com a concepção fatalista de destino social. "O social tanto quanto o natural e o material se tornam, para o homem, objeto de manipulação tecnológica" (RAMOS, 1983, p. 76).

Observa-se uma preferência geral, irrefletida, por coisas e formas de agir que são eficientes e rápidas, que economizam tempo e esforço, junto a uma constante preocupação em se controlar o futuro e à adoção de uma postura baseada na crescente propensão das pessoas de se programarem para aquilo que se propõem a fazer, revelando uma atitude e uma mentalidade tecnológica (CUPANI, 2013).

Essa mentalidade resulta de uma ampliação da tecnologia a tal ponto que ela acabou por determinar o aparecimento de um novo tipo de mente e pensamento, que avança na direção da regulamentação deliberada e da manipulação inteligente das relações entre os objetos. Não se pode, no entanto, esquecer aquelas coisas e práticas que podem centrar e orientar a vida humana. A tecnologia deve estar condicionada às práticas focais, as quais são experiências que constituem fins em si mesmas, tanto para as pessoas como para comunidades (RAMOS, 1983; BORGMANN, 1984 apud CUPANI, 2013).

É necessário que a tecnologia seja adequada aos objetivos do sistema ao qual irá servir, devendo ser considerado pelos seus membros quando da sua eleição. A escolha baseada em práticas focais proporciona uma atitude inteligente e seletiva para a tecnologia. A tecnologia deve ser o meio para uma vida boa, oportunizando uma melhor qualidade de vida, e não somente um fim a ser alcançado (RAMOS, 1981; BORGMANN, 1984 apud CUPANI, 2013).

Algumas considerações sobre tecnologia precisam ser feitas, já que o termo é empregado com diferentes sentidos, refletindo a diversidade de orientações nos estudos organizacionais e as divergentes abordagens que têm sido desenvolvidas para medir essa dimensão (PERROW, 1986; SCOT'T, 1998; VOLBERDA, 1998).

Woodward (1977), pioneira nos estudos, definiu a tecnologia considerando os sistemas de produção utilizados nas empresas, o que resultou nas categorias de produção em unidades, em massa e em processos, classificação esta que passou a ser aceita pela grande maioria dos pesquisadores, mas que foi considerada limitada por outros autores (PERROW, 1986; SCOTT, 1998; VOLBERDA, 1998).

Volberda (1998) propôs o emprego de uma abordagem mais ampla para a tecnologia, em que esta significa os meios pelos quais e a configuração na qual uma organização transforma inputs em outputs. O conceito empregado por ele permite verificar como certas tecnologias inibem ou facilitam a flexibilidade, sendo que a tecnologia se refere ao hardware (como máquinas e equipamentos) e ao software (conhecimento, técnicas e habilidades) que são empregados na transformação de recursos materiais ou informacionais em vários tipos de produtos (bens ou serviços), bem como à configuração adotada nos processos com relação ao hardware e ao software. 
Neste contexto, a relação entre tecnologia e flexibilidade não se trata somente dos imperativos relacionados às mudanças do ambiente no qual a organização está inserida e que são considerados como condicionantes para esta nova estratégia, mas inclui também uma nova forma de pensar sobre organizações e administração, numa perspectiva que se afastaria do modelo burocrático, formal, até então predominante nas organizações (VOLBERDA, 1998; DELLAGNELO, 2000).

Conforme Volberda (1998), a racionalidade organizacional própria da moderna perspectiva de gerenciamento contrasta com a visão de organização baseada na racionalidade substantiva, na qual as pessoas são encorajadas tanto a determinar se o que elas estão fazendo é apropriado como também a efetuar os ajustes que se fazem necessários. A racionalidade substancial implica que os participantes da organização possuam a habilidade para perceber ou experimentar a realidade como um todo, com coerência e significado, dando sentido para as suas ações dentro da organização.

Outra contribuição se dá a partir de Scott (1998), o qual chama atenção para o fato de que a definição de tecnologia tem sido utilizada referenciando-se ao trabalho realizado por uma organização, podendo ser reduzida a tal pondo de incluir somente o hardware, ou seja, os equipamentos, máquinas e instrumentos individuais usados na atividade produtiva. Porém há de se ter em conta o fato de que existe uma perspectiva mais ampla, que inclui as habilidades e o conhecimento dos trabalhadores na realização do trabalho, bem como as características dos objetos que estão sofrendo a ação dos trabalhadores.

Além desse aspecto, a tecnologia organizacional, apesar de ser um elemento interno, está conectada com o seu ambiente externo, sendo este uma fonte de técnicas de trabalho e ferramentas empregadas pela organização. Muitas organizações não inventam por si sós as suas tecnologias, mas as importam do ambiente, algo que pode ser visto na perspectiva dos teóricos institucionalistas como um processo isomórfico (SCOTT, 1998; DIMAGGIO; POWELL, 2005).

Há de se considerar ainda que outras variáveis podem estar envolvidas na seleção e relação da tecnologia, como a estrutura, políticas organizacionais e arranjos institucionais. Nessa visão, a tecnologia é moldada socialmente, se não uma realidade construída. Além disso, a conexão estratégica entre a tecnologia e a estrutura pode ainda se dar em função do poder exercido por algum grupo sobre a organização, conforme defendido pelos teoristas da estratégia contingencial. Isso decorre da divisão do trabalho e dos diferentes contatos exercidos pelos participantes da organização com outras pessoas, dentro e fora da organização, que podem criar perspectivas e interesses divergentes, assim como gerar novas fontes de poder que podem ser utilizadas para atingir esses interesses (SCOTT, 1998).

As organizações devem então ser observadas não como espaços constituídos por atores unificados, mas como combinações resultantes de vários grupos de interesses que se movem para dentro e para fora da organização, para cima e para baixo na escala de poder relativo, moldando a estrutura da organização (SCOTT, 1998).

Nesse sentido, Cupani (2013) chama atenção para o fato de que a tecnologia é uma forma de poder, não um mero instrumento neutro, encarnando em si valores antidemocráticos, originários de uma vinculação com o capitalismo e revelado numa cultura de administradores (managers), que vê o mundo através de uma lente baseada no controle, eficiência (medida pelo proveito atingido) e recursos, com o predomínio de uma racionalidade instrumental. Portanto é necessária certa precaução ao se tratar da flexibilidade considerandose a tecnologia, já que um aumento de tal parâmetro - levando-se em conta a adoção de tecnologias que facilitem a sua ocorrência - pode se dar não em virtude de uma maior ampliação de ações baseadas em uma perspectiva emancipadora resultante da predominância de uma racionalidade substantiva, mas sim como uma ação deliberada, instrumentalizada, com determinadas intenções políticas, consagrando relações de poder, fomentando ou impedindo determinadas formas de vida social. Dispositivos tecnológicos podem ser direcionados de tal forma a produzirem resultados que são considerados positivos somente para alguns grupos sociais, em detrimento dos demais.

Por fim, cabe ressaltar que as abordagens sobre tecnologia tiveram, predominantemente, as suas características expostas a partir de organizações manufatureiras clássicas. Porém existe um arranjo organizacional mais elaborado e intricado que lida com altos graus de complexidade e incertezas em 
sistemas produtivos, cujo caminho para gerenciar grandes tarefas complexas não se apoia em estruturas robustas e complexas, mas sim em executantes mais qualificados e flexíveis, em que a resposta é mais efetiva quando o trabalho é incerto ou quando o trabalho não envolve altos níveis de interdependência entre os trabalhadores (SCOT'T, 1998).

Nessas organizações as atividades essenciais podem ser executadas através de dois tipos gerais de arranjos. O primeiro é denominado por Scott (1998) como organização profissional autonomous. Nele as atividades são delegadas para um grupo de empregados profissionais que definem e implementam os objetivos organizacionais, estabelecendo qual será o desempenho padrão esperado e como as metas serão mantidas. Os próprios profissionais se organizam para assumir as responsabilidades da organização.

O segundo tipo, denominado por Scott (1998) de organização profissional heteronomous, é aquele em que em seu arranjo os funcionários profissionais são claramente subordinados a uma estrutura administrativa e o montante de autonomia permitida a eles é relativamente pequena. Os empregados nessa configuração estão sujeitos aos controles administrativos e sua autonomia é claramente circunscrita, estando sujeitos à supervisão rotineira, ao contrário de seus pares autonomous, que possuem autonomia.

As organizações de profissionais autonomous, diferentemente das de beteronomous, assumem variadas formas, dependendo, de maneira particular, do grau de interdependência entre os executantes individuais e os grupos executantes. Um dos pontos fortes deste profissional de "pleno-direito" é que ele é considerado capaz de tomar decisões, de controlar seu desempenho independentemente, incluindo a coordenação do trabalho com outros, se assim for requerido (SCOT'T, 1998).

\section{b. Tamanho}

Um cenário social, para atender e corresponder de forma eficaz às necessidades de seus membros, deve considerar limites mínimos ou máximos com relação ao seu tamanho. Todavia não existe nenhuma norma que determine, com precisão, antecipadamente, o limite de tamanho de um cenário, constituindo-se um problema concreto a ser resolvido através de uma investigação ad hoc, dentro do próprio contexto. No entanto há premissas que auxiliam nessa delimitação, uma delas se refere ao fato de que as relações diretas tendem a declinar na mesma proporção em que ocorre o aumento de tamanho, além de que um grande número de indivíduos, quando agrupados numa multidão, desenvolvem uma quase irresistível inclinação para o despotismo (RAMOS, 1981; ARENDT, 1997).

No atual ambiente cultural, o pressuposto que se destaca acerca do tamanho das organizações é o que enaltece o imperativo de que se deva sempre crescer, revelando a necessidade de sua revisão. Os cenários sociais para consecução de seus objetivos e o ótimo emprego de seus recursos não necessariamente resultam, de forma inevitável, em um aumento de tamanho. A perspectiva que povoa o imaginário coletivo acerca das organizações, de que "quanto maior melhor", normalmente "conduz a falsas relações pessoais, à síndrome da lei de Parkinson ${ }^{1}$, à desnecessária redundância e, finalmente, a sistemas sociais de desperdício, de limitada capacidade de auto sustentação" (RAMOS, 1981, p. 158). É preciso pensar cenários sociais que perdurem (RAMOS, 1981).

Cada cenário social possui seu limite concreto de tamanho, algo acima ou abaixo desse limite ocasiona uma perda na capacidade de se atingir de forma eficaz as suas metas, bem como de se obter o consenso mínimo necessário entre os seus membros para a sua própria preservação. Cada atividade possui uma escala que é mais apropriada para consecução dos seus objetivos. Por exemplo, conforme é mais enérgica e íntima a atividade, menor deve ser o número de pessoas que dela podem participar e maior terá de ser o número de arranjos de relacionamento a serem estabelecidos. Os cenários considerados mais amplos se tornam inapropriados naqueles espaços em que é fundamental que haja relações interpessoais diretas para que seus objetivos sejam atingidos (RAMOS, 1981; SCHUMACHER, 1983).

\footnotetext{
${ }^{1}$ A lei de Parkinson se refere à expansão do trabalho até que ele preencha todo o tempo disponível para a sua realização, resultado de observações realizadas por Cyril Northcore Parkinson no serviço civil britânico.
} 
O que se pode asseverar é que grandes tamanhos são frequentemente relacionados com organizações que operam em economias convencionais. Não existe uma regra geral para se determinar o tamanho das economias, porém se considera que economias isonômicas, por exemplo, que envolvem cooperativas e organizações que possuem administração e propriedades coletivas, são espaços em que se prescrevem tamanhos moderados. Há casos de economias, no entanto, em que para serem bemsucedidas na competição do mercado é necessário que elas adotem grandes proporções, com o emprego da divisão do trabalho, a impessoalidade e a especialização; desta forma, o grande tamanho se torna um requisito essencial para as economias convencionais. Portanto, o grande tamanho é recomendado, ao se considerar os seus méritos (RAMOS, 1981).

No caso das isonomias, estas tipicamente se caracterizam por possuir proporções moderadas, com rígida intolerância para desvios de tamanho para além de um determinado limite. São cenários cuja perspectiva está pautada na atualização pessoal, a qual, em um processo balanceado com a satisfação social, respeita o direito dos outros indivíduos de também fazê-lo. Nesse processo balanceado, pressupõe-se que sejam empregados o debate racional e o julgamento ético-valorativo das ações. Desta forma, as pessoas só conseguem ser elas mesmas em pequenos grupos abrangentes (RAMOS, 1981; SCHUMACHER, 1983).

Já as fenonomias se referem ao menor tipo concebível de cenário, podendo mesmo ser composta por uma só pessoa, sendo talvez o número de cinco membros o máximo de tamanho para uma fenonomia, sob o risco de não sobreviver além disso. Nelas prevalece o máximo de opção pessoal com uma reduzida subordinação a prescrições operacionais formais. Sobre essa questão, assevera Schumacher (1983) que quanto maior for a organização, maior será a necessidade de ordem; não que se prescreva a total ausência de normas, já que esta iria na direção da horda e da anomia, mas nas fenonomias elas são mínimas. Há de se considerar que para ocorrer a consecução de qualquer trabalho é necessária a observância de normas operacionais, portanto se preconiza a prescrição de normas contra a sua total ausência (RAMOS, 1981; SCHUMACHER, 1983).

É preciso considerar também que, em organizações com grandes tamanhos, a deliberação de todos se torna tanto mais demorada conforme aumenta a quantidade de participantes em uma assembleia, como aponta Dahl (2001). Apesar de considerar que em organizações ainda seria possível se pensar em modelos que não exijam a eleição de representantes para a deliberação, há de se ter conta, por exemplo, o tempo exigido para que cada participante se manifeste. Em uma conta simples, Dahal (2001) expõe que se forem, por exemplo, 100 participantes a se manifestar e cada um utilizar 10 minutos para expor o seu ponto de vista, seriam necessários dois dias de oito horas de reunião - não que seja impossível, porém não é nada fácil de se conseguir.

Nesse mesmo sentido, Hall (2004) destaca, através de pesquisas relacionadas ao impacto do tamanho organizacional sobre os indivíduos, que em grandes comunidades os indivíduos não conhecem nem interagem com a maioria daqueles com que entram em contato, apesar de manterem relações primárias com uma série de pessoas dentro e fora da organização. Talvez não haja diferenças na quantidade de relacionamentos realizados por uma pessoa, seja em organizações pequenas ou grandes, já que estes dependem de cada pessoa e não do tamanho da organização, porém é certo que haverá uma proporção menor de relacionamentos francos e calorosos conforme sua quantidade aumenta. O que difere é o fato de que ao se analisar, por exemplo, a participação dos membros de organizações voluntárias, de diferentes proporções, verifica-se que existe menor participação em organizações maiores.

O tamanho também pode influenciar a estrutura das organizações, como, por exemplo, no aumento do número de cargos administrativos, apesar de alguns autores questionarem essa premissa, destacando que nem sempre se observa essa relação (TERRIEN; MILLS, 1976; HALL, 2004).

Com relação à participação, conforme postula Ramos (1981) e Dahl (2001), talvez as tecnologias de comunicação venham a auxiliar na superação dessas barreiras à participação, integrando as pessoas em comunidades de interesse, porém é preciso considerar as dificuldades de se conciliar diferentes perspectivas em larga escala.

Outraquestãocom relaçãoao tamanhodas organizações se refere à influência destas sobre o moral das pessoas. As pesquisas têm demonstrado que organizações maiores levam seus membros ao estresse e a um moral 
reduzido. O caráter do grupo tende a se modificar conforme o tamanho da organização, a inserção de membros em grupos estruturalmente simples, por exemplo, produz mudanças na organização interna (TERRIEN; MILLS, 1976; HALL, 2004).

As grandes organizações tendem a tratar seus membros como membros de categorias e não como indivíduos separados. A forma adotada para se contornar tal situação ou eliminá-la é a implementação de dispositivos que favoreçam uma maior autonomia às subunidades e a descentralização (HALL, 2004).

Hall (2004) também destaca que o tamanho das organizações não só afeta as pessoas que nela trabalham, mas também aquelas que, como não membros, as contatam.

A questão é que o tamanho segue como sendo um aspecto a ser considerado pelos planejadores de sistemas sociais, principalmente no que se refere às relações sociais que se produzem dentro deles. Esse questionamento remonta a Platão, que observou que 5.040 era um número razoável de pessoas para uma população civil (TERRIEN; MILLS, 1976).

Portanto, ao se tratar do tamanho dos enclaves, como postula Ramos (1981), deve-se ter em conta que os limites deverão ser estipulados ad hoc, prevalecendo a expertise, o conhecimento e o bom senso dos planejadores do sistema social, ou seja, in loco, a partir da percepção dos atores.

\section{c. Espaço}

O sistema de mercado nos últimos séculos se expandiu de tal forma que se tornou o principal ordenador da vida pessoal e comunitária, ocupando os diferentes espaços reservados aos sistemas sociais. Isso é visível quando se observa, por exemplo, a arquitetura das cidades contemporâneas, a qual reflete as exigências do mercado (RAMOS, 1981).

O que ocorre é o constante aumento da artificialização do meio ambiente. A esfera natural é de forma crescente e constante substituída por uma esfera técnica; os objetos culturais na atualidade tendem a se tornar cada vez mais técnicos e específicos, produzidos e localizados para melhor responder aos objetivos previamente estabelecidos. Já as ações, tendem a se tornar cada vez mais ajustadas e racionais (SANTOS, 2008).

Conforme Santos (2008, p. 30), “o caminho secular que conduziu a sociedade humana à necessidade cotidiana de medida, padronização, ordem e racionalização" fez com que o próprio espaço passasse a possuir igual conteúdo racionalizado, em função da intencionalidade manifesta na escolha de "seus objetos, cuja localização, mais do que antes, é funcional para os desígnios dos atores sociais capazes de uma ação racional".

A matematização dos espaços propicia a matematização da vida social, consonante com os interesses hegemônicos, ou seja, subordinada aos que impõem as mudanças. "Tudo é disposto para que os fluxos hegemônicos corram livremente, destruindo e subordinando os demais fluxos" (SANTOS, 2008, p. 31). A partir dessa lógica, instalam-se, ao mesmo tempo, "não só as condições do maior lucro possível para os mais fortes, mas também as condições para a maior alienação possível para todos. Através do espaço, a mundialização, em sua forma perversa, empobrece e aleija" (SANTOS, 2008, p. 31).

O espaço deve ser considerado como o teatro obrigatório da ação, o domínio da liberdade, sendo dinâmico e unitário, onde se encontram a materialidade e a ação humana. "Seria o conjunto indissociável de sistemas de objetos, naturais ou fabricados, e de sistemas e de ações, deliberadas ou não. A cada época, novos objetos e novas ações vêm juntar-se às outras, modificando o todo, tanto formal quanto substancialmente" (SANTOS, 2008, p. 46).

O espaço de certa forma afeta e possui a capacidade de moldar a vida das pessoas, os espaços que são dados para viver aos indivíduos podem de alguma maneira alimentar ou dificultar o desenvolvimento psíquico deles dentro da sua singularidade como pessoas. O espaço pode ser um ambiente que facilite ou restrinja a descarga de tensões. O seu correto tratamento é uma forma de se estimular a atmosfera psicológica apropriada para os objetivos específicos de um determinado sistema social (RAMOS, 1981).

Os estudos realizados sobre o espaço têm se limitado, sobretudo, a questões relacionadas aos processos de produção e distribuição de bens e à prestação de 
serviços. Porém existem implicâncias com relação ao espaço que vão além dos propósitos econômicos e que são esquecidas tanto por leigos como também por arquitetos e especialistas em organizações, que supostamente deveriam ser os que melhor as compreendem na sua totalidade (RAMOS, 1981).

Nas isonomias e fenonomias e suas formas mistas, o espaço desempenha um papel especial para seu bom funcionamento, questões como solidão, privacidade, reserva, intimidade, anonimidade, território pessoal e órbita individual são e devem ser consideradas. A expectativa é que prevaleçam espaços sócioaproximadores, que teoricamente promovem relações de primeiro grau, que são características dessas organizações (HALL, 2005; RAMOS, 1981).

Já nas economias os espaços sócio-afastadores parecem prevalecer, apesar de os sócio-aproximadores também se mostrarem como sendo necessários, mesmo nesse enclave. Porém no sistema de mercado os cidadãos são condicionados a uma percepção e uso do espaço em que a perspectiva adotada é a técnica, a qual define o seu comportamento (RAMOS, 1981).

A organização do espaço pode ser pensada como um continuum, em que em uma das suas extremidades estariam aqueles espaços que não fazem uso de nenhuma organização, que estão em uma confusão permanente, ocupados por pessoas que não efetuam uma classificação das atividades e artefatos de acordo com um plano espacial uniforme, coerente e previsível. $\mathrm{Na}$ outra extremidade da escala, estaria a linha de montagem, com uma organização precisa dos objetos tanto no tempo como no espaço (HALL, 2005).

Considerando esse continumm, cada cenário social possui as suas exigências no que se refere ao espaço e que são inerentes a ele. Não existe, porém, uma dicotomia do tipo bom - ruim. "O que é realmente desejável é que exista flexibilidade e congruência entre projeto e função para que haja uma variedade de espaços e as pessoas possam se envolver ou não, como exijam a ocasião e a disposição de espírito" (HALL, 2005, p. 138).

Essa preocupação está associada às representações do espaço (o concebido), que são as relações de produção e a ordem que por ela é imposta e que estão vinculadas aos conhecimentos, aos signos, aos códigos e às relações frontais (LEFEBVRE, 1991).
$\mathrm{Na}$ produção do espaço social existe a coadunação de três aspectos: a prática espacial, que envolve a produção, reprodução, os lugares especificados e conjuntos espaciais próprios a cada formação social; as representações do espaço, ou espaço concebido, aquele dos cientistas, dos planificadores e dos urbanistas, entre outros, que identifica o vivido e percebido, e que é o espaço dominante em uma sociedade; e os espaços de representações, que são portadores de símbolos clandestinos e subterrâneos da vida social. Esses três aspectos desenvolvem uma relação dialética entre si, ou seja, envolvendo o percebido, o concebido e o vivido (LEFEBVRE, 1991).

Lefebvre (1991) defende que a utilização do conceito dessas práticas, representações da produção, pode servir como instrumento (operatório) para análise de espaços, assim como das sociedades que os geraram e deles se apoderaram, pois daí decorreria uma história do espaço que não obrigatoriamente coincide com as periodizações admitidas, mas que, tendo em vista a passagem de um modo de produção a outro e as suas influências, permitiria tal análise.

Lefebvre (1991) identifica então quatro tipos de espaços, os quais representariam a periodização de diferentes processos produtivos, a saber: o espaço absoluto, o histórico, o abstrato e o diferencial.

O espaço absoluto se refere a fragmentos da natureza, locais escolhidos com base nas suas qualidades intrínsecas (cavernas ou cumes, fonte ou rio), mas que cuja consagração, por fim, acaba por esvaziálos de muitas dessas características e particularidades naturais, sendo o espaço-natureza povoado por forças políticas. De maneira típica, a arquitetura acaba por subtrair da natureza os lugares e os transfere para a esfera política por meio de uma mediação simbólica (LEFEBVRE, 1991).

A partir desse espaço ocorre a emersão de outro, relativizado e histórico, que traz consigo a plenitude invisível do espaço político que se instaurou no vazio de um espaço natural subtraído da natureza. A historicidade quebra para sempre a naturalidade e instaura sobre as suas ruínas o espaço de acumulação (de toda riquezas e recursos: os conhecimentos, as técnicas, o dinheiro, os objetos preciosos, as obras de arte e os símbolos). No transcorrer desse período, a atividade produtiva, a mão de obra, deixa de se confundir com a reprodução que perpetua a vida 
social, ela se torna independente desse processo, ficando presa à abstração, o trabalho social se torna abstrato, o espaço abstrato (LEFEBVRE, 1991).

O espaço abstrato funciona "objetalmente" como um conjunto de coisas/signos e suas relações formais: vidro e pedra, concreto e aço, ângulos e curvas, cheio e vazio. Esse espaço, que tem por característica ser formal e quantificado, nega as diferenças, sejam elas provenientes da natureza ou do tempo (histórico), ou ainda aquelas que se originam do corpo, como a idade, gêneros e etnias. A significância desse conjunto remete a uma espécie de sobressignificação, que escapa aos sentidos, ao funcionamento do capitalismo, o qual é ao mesmo tempo evidente e dissimulado. As formas dominantes de espaço, dos centros de poder e riqueza, se esforçam para moldar os espaços que dominam (ou seja, os espaços periféricos), fazendo uso, muitas vezes, de meios violentos para reduzir os obstáculos e resistências que porventura venha a encontrar (LEFEBVRE, 1991).

O espaço abstrato é uma produção do capitalismo e do neocapitalismo, o qual contém o mundo da mercadoria, sua lógica e as suas estratégias em escala mundial, juntamente com o poder do dinheiro e do Estado político (LEFEBVRE, 1991).

O espaço abstrato possui um funcionamento extremamente complexo, que implica uma passividade, um silêncio dos usuários, assim como um pacto de não agressão, um quase contrato de não violência. Nele, em determinados lugares, são valorizados alguns tipos de relações, considerando-se aspectos "proxêmicos", não havendo lutas para ocupar os espaços. As pessoas assumem uma disposição socialmente condicionada na qual as regras e normas de operações são peculiares a determinados sistemas episódicos, que passam a ser consideradas como regras e normas de conduta para todos de um modo em geral. (LEFEBVRE, 1991; RAMOS, 1981; HALL, 2005).

Apesar do pessimismo resultante, o espaço abstrato possui contradições específicas, as quais são em grande parte derivadas de outras antigas contradições, oriundas do tempo histórico, que são agravadas ou atenuadas e que eventualmente podem conduzir esse espaço ao seu fim. Como consequência, o espaço abstrato engendra um novo espaço, denominado diferencial, o qual, de forma contrária ao abstrato, necessita de um processo de acentuação das diferenças para surgir, motivo pelo qual recebe essa denominação (LEFEBVRE, 1991).

O espaço diferencial reúne aquilo que o abstrato separa, as funções, os elementos e os momentos da prática social. Ele colocaria um fim naquelas localizações que rompem tanto com a unidade do corpo (individual e social) como com o corpus das necessidades humanas e o corpus do conhecimento. De forma contrária ao abstrato, discerniria aquilo que é confundido, por exemplo, as relações sociais com as relações familiares (LEFEBVRE, 1991).

\section{d. Tempo}

O tempo é uma categoria básica da existência humana, penetra nos conceitos básicos da análise organizacional, porém costuma ser negligenciado ou raramente ter seu sentido discutido. A mensuração da sua passagem se dá de diversas maneiras, segundos, minutos, horas, dias, meses anos, décadas, séculos e eras, como se tudo estivesse assentado em uma única escala temporal objetiva. As diferentes sociedades (ou subgrupos) cultivam os sentidos de tempo de maneiras bem distintas, as quais são criadas necessariamente por meio de práticas e processos materiais que reproduzem a vida social. Cada forma distinta de produção ou formação social envolve um agregado particular de práticas e conceitos do tempo (HALL, 1990; BUTLER, 1995; HARVEY, 2012).

Nas sociedades modernas vários sentidos de tempo se entrecruzam. As rotinas e os movimentos cíclicos transmitem certa sensação de segurança às pessoas, em um mundo cujo impulso geral do progresso parece indicar sempre para frente e para o alto. A ordenação simbólica que é dada ao tempo propicia uma estrutura para a experiência, a partir da qual se aprende quem ou o que se é em uma sociedade. No século XX, o tempo se organizou de acordo com o desenvolvimento das sociedades industriais e das cidades, permitindo o emprego do tempo linear do relógio, o controle de forma disciplinar das relações de trabalho (TONELLI, 2008; HARVEY, 2012).

O tempo do trabalho, no entanto, passou não só a controlar e regular as atividades dentro das organizações, mas extrapolou o seu espaço e avançou sobre as demais relações humanas, ou seja, para os 
demais enclaves da vida humana. O tempo do trabalho passou a regular a vida de maneira generalizada. O movimento de pessoas e mercadorias passou a ser regulado por ele, seja dentro ou fora das cidades, em uma espécie de sincronização da vida (RAMOS, 1981; TOFFLER, 1998; TONELLI, 2008).

Porém, o tempo nas organizações formais não é o mesmo daquele característico nos sistemas sociais, em que prevalecem a intimidade e a intensa reciprocidade pessoal. Nesse sentido, Ramos (1981) propõe uma tipologia diferenciada para o tempo, constituída pelas seguintes categorias: tempo serial, linear ou sequencial; tempo convival; tempo de salto - leap time; e tempo errante.

Nas economias prevalece o tempo serial, o qual não satisfaz as necessidades humanas que se referem a atividades cujo tempo não possa ser estabelecido em termos de séries. A sociedade centrada no mercado, considerando a sua orientação temporal, serializa o tempo dos seus membros de tal forma que estes passam a ter dificuldade em se engajar em outras atividades que requeiram outro tipo de orientação temporal (RAMOS, 1981).

Nas isonomias o que prevalece é o espaço para o exercício da convivência, o requisito temporal exigido é o da experiência de tempo, em que o indivíduo desfruta dos ganhos que obtém com seus relacionamentos, ganho este que não é medido quantitativamente, mas sim a partir de uma gratificação profunda por ter se libertado das pressões que impedem a sua autorrealização pessoal, portanto é o espaço do tempo convival (RAMOS, 1981).

Esse tempo convival é catártico, a experiência individual encoraja a interagir com os outros sem o uso de máscaras, fachadas, e vice-versa. A experiência se revela libertadora, proporcionando o relaxamento, as pessoas tendem a ter mais confiança nas outras pessoas e a expressar seus sentimentos mais profundos com autenticidade. Os outros não são objetos, mas sim pessoas, a aceitação e a estima se dão pelo o que as pessoas são, independentemente das suas posições empresariais ou status no ambiente competitivo do mercado. O tempo serial é esquecido quando os indivíduos estão envolvidos na experiência do tempo convival (RAMOS, 1981).

O tempo de salto se refere a um tipo muito pessoal de experiência temporal, cuja qualidade e ritmo estão diretamente relacionados à intensidade com que o indivíduo anseia por criatividade e autoesclarecimento. É o impulso temporal das fenonomias. A sua ocorrência normalmente é relacionada com informes de progressos marcantes obtidos por pessoas criativas (RAMOS, 1981).

O tempo errante é caracterizado por possuir uma direção inconsistente, as pessoas que o vivenciam possuem uma experiência imprecisa de sua agenda existencial, se é que é possível julgar a existência de alguma espécie de agenda. O tempo errante se relaciona a pessoas anômicas ou quase anômicas (RAMOS, 1981).

Nos estudos organizacionais, o tempo tem sido basicamente abordado sob a perspectiva dos sistemas econômicos, sendo tratado como uma mercadoria ou ainda como um aspecto da linearidade do comportamento organizacional. Essa visão do tempo, no entanto, não reflete a realidade observável atualmente nas organizações. Diante das diferentes contingências a que as organizações são defrontadas no seu dia a dia, surgem peculiaridades que interferem nessa harmonia temporal. As atividades do mundo do trabalho nem sempre se referem a um ritmo imposto por máquinas, mas envolvem também outras possibilidades de processos e de trabalho (RAMOS, 1981; HASSARD, 2009).

Isso gera novas lógicas dentro das organizações, como novas formas organizacionais, formas flexíveis, em que os controles dos tempos não são tão finitos e determinados da maneira que a perspectiva racional imagina, podendo ocorrer também que os grupos de trabalho construam os seus próprios sistemas de mensuração do tempo, não seguindo prescrições impostas (HASSARD, 2009).

Essa mesma diferenciação é observável nas duas formas contrastantes de lidar com o tempo descritas por Hall (2005), o monocrônico e o policrônico. O monocrônico é associado aos grupos com baixo envolvimento pessoal, que procuram compartimentar o tempo. Eles fazem a programação de uma atividade para cada momento e ficam desorientados se tiverem de lidar com várias coisas de uma só vez. As pessoas policrônicas, por sua vez, talvez por se envolverem muito mais umas com as outras, tendem a manter diversas atividades em andamento ao mesmo tempo, 
como malabaristas, acumulando várias tarefas de forma simultânea (HALL, 2005).

Tendo-se em conta as organizações isonômicas e fenonômicas e as categorias de tempo convival e de salto (leap time), é possível inferir que nesses sistemas sociais a expectativa é a de identificar características de tempo que se aproximam da forma policrônica, que privilegia o contato pessoal e a interação, características desses espaços.

Nas isonomias, por exemplo, o enclave é propício para o exercício da convivência, “(...) e o seu principal requisito temporal é uma experiência de tempo em que aquilo que o indivíduo ganha em seus relacionamentos com as outras pessoas não é medido quantitativamente, mas representa uma gratificação profunda (...)" (RAMOS, 1981, p. 169).

Nas fenonomias, o tempo de salto se caracteriza por ser uma experiência temporal, pessoal, em que a qualidade e o ritmo revelam o desejo do indivíduo pela criatividade e o autoesclarecimento. É visto como um momento muito importante na vida de uma pessoa criativa e perscrutadora, seja de maneira isolada ou na companhia de outras pessoas que também estejam sintonizadas com o mesmo tipo de indagação, ou seja, que compartilhem as mesmas ideias, ponto que revela a necessidade de interação entre elas (RAMOS, 1981).

Nas economias, por sua vez, a perspectiva é a de que predomine o tempo serial ou monocrônico, característicos de espaços em que prevalece a naturalização da quantificação do tempo, tornandose algo rotineiro e que define uma ordem lógica cronológica para a execução das atividades. Esse tempo é considerado um bem escasso, limitado, tendo o seu valor realçado. É uma mercadoria que pode ser empregada para se obter dinheiro, ou que o dinheiro pode comprar. O tempo deve ser investido de forma a render dinheiro algum tempo depois, e não para a autorrealização pessoal (RAMOS, 1981; HASSARD, 2009).

A mensuração do tempo organizacional, no entanto, não pode estar adstrita somente à medição fornecida pelo relógio ou outro tipo de cronômetro, pois conforme Butler (1995) o tempo está ligado a eventos, e o ritmo desses eventos não necessariamente coincide com o tempo do relógio.
Butler (1995) propõe então quatro clusters para significar as experiências do tempo: relógio, orgânico, estratégico e espasmódico. Essas variáveis abrem a possibilidade de se efetuar uma comparação das experiências de tempo.

O tempo do relógio é aquele associado ao ritmo do balanço de um pêndulo, mecânico, rígido, inflexível e pré-determinado. Nesse tempo a ênfase está na sincronização das atividades em uma ordem imóvel e pré-determinada. As experiências do passado são transpostas para o futuro, sendo os eventos futuros previstos a partir do conhecimento codificado do passado. É o tempo que pode ser associado às burocracias (BUTLER, 1995).

O tempo orgânico é aquele que é percebido como um processo de crescimento natural pelo qual as ideias e ações se desenvolvem, por meio de consensos e congruências sobre os futuros possíveis. O passado é relativamente não codificado e ligado de forma indeterminada aos futuros possíveis. A unidade do tempo orgânico tende a refletir o ciclo de crescimento natural, tendo como medida o fato de as ideias e ações estarem prontas, independentemente do relógio. Esse é o tempo das organizações coletivas (BUTLER, 1995).

O tempo estratégico se refere àquele que é percebido como dependente das ações de outras pessoas, cujas visões de futuros possíveis não são congruentes com as nossas, mas que têm o poder de afetar o nosso futuro. O passado é codificado dentro de um conjunto homogêneo de regras. Esse é o tempo experimentado em jogos, mercados e política, em que o movimento é seguido por um contramovimento, executado por parte de uma oposição, e pelo movimento seguinte de aguardar o movimento contrário. Esse é o tempo experimentado em situações nas quais as pessoas interagem e os participantes tornam-se "jogadores" que precisam pensar estrategicamente para fazer suas escolhas de ação, dependendo das escolhas que os outros jogadores irão realizar. É o tempo das organizações estratégicas ou de jogos (BUTLER, 1995).

O tempo espasmódico é aquele percebido como elástico, que se torce e retorce como um peixe fora d'água, moldando as mentes à medida que ocorre. Essa experiência de tempo se encaixa em uma visão heterogênea e codificada do passado e com uma visão 
de futuro sobre a qual os participantes têm dificuldade em concordar (incongruência). As escolhas conectando problemas e soluções tendem a ocorrer de forma aleatória em uma escala de tempo que parece ter pouca relação com o tempo do relógio. Esse é o tempo das organizações do tipo espasmódicas ou "garbage-can" (BUTLER, 1995).

\section{Quadro de análise}

Para a análise das organizações, conforme o objetivo deste ensaio, é apresentada uma proposta de quadro de análise que permite o estudo de organizações, incluindo-se aquelas consideradas como ausências, ou seja, organizações que muitas vezes fazem uso de conhecimentos ditos ordinários ou vulgares, os quais insistentemente não são reconhecidos pelo modelo da razão indolente. Para tal, faz-se uso das características esboçadas por Ramos (1981), com o aporte teórico de outros autores, como Hall (1990); Gurvitch (1969); Scott (1998); Ramos (1983); Lefebvre (1991); Butler (1995); Volberda (1998); Dellagnelo e Machado da Silva (2000); Hall (2004); Santos (2008); e Cupani (2013).

O quadro de análise foi elaborado considerando-se somente três enclaves, desconsiderando-se a horda, a anomia e o isolado, pois para que ocorra a consecução de qualquer trabalho é necessária a observância de normas operacionais, fator ausente nessas dimensões (RAMOS, 1981).

Quadro 1. Características das dimensões dos espaços sociais

\begin{tabular}{|c|c|c|c|}
\hline Dimensões & Economia & Isonomia & Fenonomia \\
\hline Tecnologia & $\begin{array}{l}\text { - Flexibilidade adotada em } \\
\text { função do mercado } \\
\text { - Heteronomous } \\
\text { - Eficiência } \\
\text { - Dominação, controle, exercício } \\
\text { do poder }\end{array}$ & $\begin{array}{l}\text { - Flexibilidade espontânea } \\
\text { - Autonomous } \\
\text { - Realização humana } \\
\text { - Deliberada }\end{array}$ & $\begin{array}{l}\text { - Flexibilidade espontânea } \\
\text { - Autonomous } \\
\text { - Realização humana } \\
\text { - Deliberada }\end{array}$ \\
\hline Tamanho & $\begin{array}{l}\text { - Grande tamanho, requisito } \\
\text { viável para economias } \\
\text { convencionais que competem } \\
\text { no mercado } \\
\text { - Pessoas como categorias }\end{array}$ & $\begin{array}{l}\text { Proporções moderadas, } \\
\text { com rígida intolerância para } \\
\text { desvios de tamanho além } \\
\text { do determinado } \\
\text { - Pessoas como indivíduos }\end{array}$ & $\begin{array}{l}\text { - Menor tipo concebível } \\
\text { de cenário social, pode se } \\
\text { compor de uma só pessoa. } \\
\text { Limite em torno de cinco } \\
\text { pessoas } \\
\text { - Pessoas como indivíduos }\end{array}$ \\
\hline Espaço & $\begin{array}{l}\text { - Sócio-afastador } \\
\text { - Abstrato } \\
\text { - Conteúdo racionalizado }\end{array}$ & $\begin{array}{l}\text { - Sócio-aproximador } \\
\text { - Diferencial } \\
\text { - Teatro da ação, domínio da } \\
\text { liberdade }\end{array}$ & $\begin{array}{l}\text { - Sócio-aproximador } \\
\text { - Diferencial } \\
\text { - Teatro da ação, domínio da } \\
\text { liberdade }\end{array}$ \\
\hline Tempo & $\begin{array}{l}\text { - Tempo serial, linear ou } \\
\text { sequencial } \\
\text { - Monocrônico } \\
\text { - Relógio }\end{array}$ & $\begin{array}{l}\text { - Tempo convival } \\
\text { - Policrônico } \\
\text { - Orgânico }\end{array}$ & $\begin{array}{l}\text { - Tempo de salto } \\
\text { - Policrônico } \\
\text { - Orgânico }\end{array}$ \\
\hline
\end{tabular}

Fonte: Elaborado pelo autor. 
Cabe ressaltar que essas características, como salientado por Ramos (1981) quando da apresentação do paradigma paraeconômico, são modelos ideais, não se esperando encontrá-las de forma pura, mas sim combinadas de diferentes maneiras, em maior ou menor grau nos sistemas sociais. A proposta aqui apresentada para análise das organizações tem objetivos heurísticos, não se pressupondo que sejam caracterizadas como definitivas, certas ou erradas, ou ainda algo a ser buscado; ou seja, o propósito é servir como instrumento para o raciocínio acerca dessas organizações e suas práticas, conhecê-las, como salienta Ramos $(1981,1983)$.

\section{Considerações finais}

Este ensaio teve por objetivo apresentar uma proposta de análise organizacional voltada às organizações culturais, cuja gestão se revela como sendo um grande guarda-chuva que abriga uma variada gama de atividades, com uma grande diversidade de lógicas, práticas e padrões de organizações (SUMMERTON; KAY; HUTCHINS, 2006). A própria definição de cultura baseada nas dimensões antropológica e sociológica já expõe as diferenças envoltas nessas organizações. A primeira considera a cultura a partir das interações entre os indivíduos, que organizam suas formas de pensar e sentir, construindo os seus valores, manejando suas identidades e diferenças, e estabelecendo as suas rotinas, o que gera um conjunto de atitudes, crenças, costumes e práticas que são comuns para o grupo, ou ainda compartilhadas por estes (BOTELHO, 2001; THROSBY, 2003). Já a dimensão sociológica não é constituída através do cotidiano dos indivíduos, ela é resultado de uma produção elaborada, especializada, seu objetivo é o de revelar e construir determinados sentidos e atingir a um público específico, fazendo uso de certos meios característicos de expressão. Para a concretização desse intento, é necessário o emprego de um conjunto de fatores que possibilitem ao indivíduo tanto o desenvolvimento e o aperfeiçoamento de seus talentos como também a disponibilidade de canais que lhe propicie a oportunidade de expressá-los (BOTELHO, 2001). As organizações culturais podem atuar, então, tanto dentro dessas dimensões como, ainda, transitar entre elas de acordo com os objetivos pretendidos em determinado momento.
Portanto os estudos dessas organizações não podem ser restritos somente a uma visão baseada no mainstream, é preciso se considerar outras realidades, como as ausências, ou seja, organizações que muitas vezes fazem uso de conhecimentos ditos ordinários ou vulgares, os quais insistentemente não são reconhecidos pelo modelo da razão indolente, mas que podem ser criados e usados tanto para dar sentido as nossas vidas como para proporcionar o efetivo emprego do conhecimento científico acumulado, num contributo positivo para a felicidade das pessoas e sua autorrealização (SANTOS, 2002; RAMOS, 1981).

Estas organizações, como as isonomias e fenonomias, diferentemente daquelas centradas unicamente no mercado, possuem características que privilegiam outros aspectos da vida humana associada, como "a boa vida", a partir de uma multiplicidade de cenários, o que é um dos requisitos para a autorrealização pessoal (RAMOS, 1981, grifo do autor). Elas podem, ainda, ser associadas a outras formas de se organizar, alternativas, ou seja, são organizações que não fazem uso de modelos extremamente burocráticos ou que estejam pautados em uma racionalidade puramente instrumental ou funcionalista, adotando práticas estritamente gerencialistas ou fazendo uso de novas práticas sob o manto de um pensar baseado unicamente no modelo dominante, aproximando-se daquilo definido por Paula (2002) como harmonias administrativas.

Por isso, o quadro de análise reúne em seu interior as características relacionadas às dimensões de tecnologia, tamanho e tempo que estejam associadas aos objetivos dessas organizações, ou seja, em que tanto o agir quanto as decisões e escolhas sejam feitas não em função de estimativas utilitárias de consequências, que até podem ocorrer por acidente, mas sim considerando que as causas finais, e não somente as eficientes, influenciam o mundo em geral (RAMOS, 1981).

Nesse sentido o estudo dessas organizações e a sua compreensão, a partir de elementos de análise que estejam alinhados as suas características, se tornam relevantes, pois caminhariam na direção de proporcionar subsídios para o desenvolvimento de elementos emancipadores na sociedade, em uma visão contrária à perspectiva unidimensional que tem predominado, em que o mercado, como aponta Ramos (1981), se tornou central na orientação da vida 
das pessoas. É preciso desvelar essas práticas, expô-las e assimilá-las.

A expectativa é que o quadro de análise possa contribuir para o estudo dessas organizações e na compreensão de suas práticas, muito das quais se baseiam em aspectos relacionados à dádiva e doação, que, ao contrário da simples venda de uma mercadoria, possuem a expectativa da criação de laços afetivos e o estabelecimento de um relacionamento entre aqueles que estão envolvidos, de modo contrário à simples venda de uma mercadoria (HYDE, 2010).

Conforme Maus (2003), em sociedades baseadas nos princípios da dádiva e doação, prevalecem motivos de vidas e de ação baseados na alegria do doar em público; no prazer do dispêndio artístico generoso; no prazer da hospitalidade e da festa privada e pública; na honra. O desprendimento e a solidariedade corporativa não são vistos, nessas sociedades, como palavras vãs nem tampouco contrariam as necessidades do trabalho, há o predomínio de uma vida social normal, sem o prevalecimento único do utilitarismo. Os sujeitos agem considerando a si mesmos, os subgrupos e a sociedade, defendendo seus interesses tanto pessoalmente como em grupo, em um sistema de prestações totais.

Além disso, é preciso entender melhor a relação dessas organizações com o mercado, e as tensões que podem se originar de tal aproximação. Considerase a importância de se ir além da pura lamentação pelo eventual triunfo da lógica do mercado sob o mundo vivido, em uma visão maniqueísta, que desconsidera a existência simultânea dos diferentes enclaves. É necessário um aprofundamento acerca do relacionamento entre as dimensões comerciais e artísticas, entre as organizações isonômicas e fenonômicas e o mercado. O desafio é pelo desenvolvimento de uma teoria organizacional que aborde o relacionamento entre essas diferentes dimensões, comerciais e artísticas, de tal forma que seja possível conciliar a possibilidade de que essas organizações possam se desenvolver sem ter as suas características substantivas ameaçadas pelo espaço econômico (VIZEU, 2009; SOUZA; CARRIERI, 2011).

Essa teoria, arriscando possibilidades, deveria ir à mesma direção da teoria econômica substantiva proposta por Polanyi e citado por Godelier (1976), sendo capaz de abarcar a entrada de todas as formas possíveis de organizações, não designando princípios formalizados de comportamentos, apenas as funções específicas de certas relações sociais, função esta que seria seu próprio conteúdo, a própria substância dessas relações (GODELIER, 1976).

Conforme Polanyi, Arensberg e Pearson (1976), a teoria substantiva da economia, diferentemente da formal, é caracterizada como um processo institucionalizado de interação entre o homem e o meio, em que o homem, de maneira continuada, é dotado dos meios materiais para satisfazer suas necessidades. Ela deriva da dependência entre o homem, a natureza e os seus semelhantes para conseguir seu sustento (POLANYI; ARENSBERG; PEARSON, 1976).

O significado substantivo não implica a eleição nem a escassez de recursos, diferentemente do significado formal, que implica uma série de normas que regem a eleição entre os usos alternativos de meios escassos. $\mathrm{Na}$ abordagem substantiva o sustento do homem não tem por que implicar a necessidade de eleições, e se estas existem não tem por que estarem determinadas pelo efeito limitador de uma escassez dos recursos. $\mathrm{Na}$ realidade algumas das condições físicas e sociais mais importantes de sobrevivência podem estar disponíveis, sem maiores limitações (POLANYI, ARENSBERG e PEARSON, 1976).

O que ocorre atualmente, no entanto, é que a concepção corrente do econômico funde os dois significados, de subsistência e de escassez, sem suficiente consciência dos perigos que tal fusão envolve para a clareza de pensamento, o que leva todos a pensarem que para sobreviver é preciso disputar recursos (POLANYI, ARENSBERG e PEARSON, 1976).

Outro ponto de apoio para o desenvolvimento dessa teoria estaria no próprio Ramos (1981), que expõe a necessidade da conceptualização de uma abordagem substantiva da organização e da reformulação das teorias organizacionais sobre novos fundamentos epistemológicos. Nessa proposta, como diretrizes, Ramos (1981) destaca que o homem possui diferentes tipos de necessidades, requerendo múltiplos cenários sociais; que o sistema de mercado só consegue atender parcialmente às necessidades humanas, sendo condicionado a imperativos econômicos; que diferentes cenários organizacionais pressupõem diferentes categorias de tempo e espaço vital; que a diferentes cenários sociais pertencem diferentes 
sistemas cognitivos; e que são necessários diferentes enclaves para atender aos diferentes cenários sociais.

Portanto, é preciso desvelar essas outras possibilidades, de tal forma que organizações mais próximas a outros enclaves sociais que não o econômico não sejam vistas como "pontos fora da curva", implicando a eleição de receitas que objetivam adequá-las à realidade esperada. É preciso compreendê-las e, principalmente, aprender com esses conhecimentos, os quais muitas vezes são ocultados pela prática hegemônica. Para tal, Ramos (1983) recomenda o emprego de uma atitude metódica, que não admita a existência na realidade social de objetos sem pressupostos, demandando uma noção de mundo que considera que os objetos em parte são constituídos pela perspectiva em que estão inseridos.

Considerando-se essas possibilidades, como estudos a serem realizados com o emprego do quadro de análise proposto, sugere-se a análise entre organizações que compõem os diferentes enclaves, como forma de compreender seus pressupostos subjacentes; a análise da congruência entre objetivos e práticas, considerando seus fins; a análise das interferências dos diferentes enclaves sobre as organizações; o estudo das modificações sofridas pelas dimensões ao longo dos tempos, considerando os aspectos de cada enclave; e a análise dos enclaves predominantes nos diferentes setores organizacionais, entre outros. Acredita-se serem estas propostas iniciais para empregabilidade do quadro de análise, havendo outras possibilidades a serem descortinadas.

\section{Referências}

ARENDT, Hannah. A Condição Humana. 8. ed. Rio de Janeiro: Forense Universitária, 1997.

BENDIXEN, P. Managing art: an introduction into principles and conceptions. Wien; Berlin; Münster: Lit, 2010.

BOTELHO, I. Dimensões da cultura e políticas públicas. São Paulo em Perspectiva, São Paulo, v. 15, n. 2, p. 73-83, abr. 2001.

BUTLER, R. Time in organizations: its experience, explanations and effects. Organization Studies.
London, vol. 16/6, p. 925-950, Nov. 1995.

CUPANI, A. Filosofia da tecnologia: um convite. $2^{a}$ ed. Florianópolis: Ed. da UFSC, 2013.

DAHAL, R. A. Sobre a democracia. Brasília: Editora Universidade de Brasília, 2001.

\section{DELLAGNELO, E. H. L. Novas formas}

organizacionais: ruptura com o modelo burocrático? 2000. 192 f. Tese (Doutorado em Engenharia de Produção e Sistemas) - Curso de Pós-Graduação em Engenharia de Produção, Universidade Federal de Santa Catarina, Florianópolis, 2000.

DELLAGNELO, E. H. L.; MACHADO-DASILVA, C. Novas Formas Organizacionais: onde se encontram as evidências empíricas de ruptura com o modelo burocrático de organizações? Organizações e Sociedade O\&S, v. 7, n. 19, 2000.

DIMAGGIO, P. J.; POWELL, W. W. A gaiola de ferro revisitada: isomorfismo institucional e racionalidade coletiva nos campos organizacionais. Revista de Administração de Empresas - RAE, São Paulo, v. 45, n 2, abr./jun. 2005.

GODELIER, M. Presentación. In: POLANYI, K.; ARENSBERG, C. M.; PEARSON, H. W. Comercio y mercado en los imperios antiguos. Barcelona: Editorial labor, S.A., 1976. p. 9-37.

GURVITCH, G. Os quadros sociais do conhecimento. Rio de Janeiro: Moraes Editores, 1969.

HALL, E. T. The silent language. $1^{\text {a }}$. ed. Garden City: Doubleday \& Company, 1990.

HALL, E. T. A dimensão oculta. São Paulo: Martins Fontes, 2005.

HALL, R. H. Organizações: estruturas, processos e resultados. 8. ed. São Paulo: Prentice Hall, 2004.

HARVEY, D. Condição Pós-Moderna. 22. ed. São Paulo: Edições Loyola Jesuítas, 2012.

HASSARD, J. Imagens do tempo no trabalho e na organização. In: CALDAS, M.; FACHIN, 
R.; FISCHER, T. Handbook de Estudos

Organizacionais: reflexões e novas direções. 1. ed.

São Paulo: Atlas, v. 2, 2009. Cap. 10, p. 190-216.

\section{HEIDEMANN, F. G.; SALM, J. F.. Políticas} públicas e desenvolvimento: bases epistemológicas e modelos de análise. Brasília: Editora Universidade de Brasília, 2009.

HYDE, L. A dádiva: como o espírito criador transforma o mundo. Rio de Janeiro: Civilização Brasileira, 2010.

LEFEBVRE, H. The Production of Space (N. S. Donald, Translated). Blackwell Publishing, London, 1991.

MAUSS, M. Sociologia e antropologia. São Paulo: Cosac Naify, 2003.

PAULA, A. P. P. Tragtemberg revisitado: as inexoráveis harmonias administrativas e as burocracias flexíveis. Revista de Administração

Pública, Rio de Janeiro, v. 36, n. 1, 2002.

PERROW, C. Complex Organizations: a critical essay. 3. ed. New York: Random House, 1986.

POLANYI, K.; ARENSBERG, C. M.; PEARSON, $\mathrm{H}$. W. Comercio y mercado en los imperios antiguos. Barcelona: Labor Universitaria Monografías, 1976.

RAMOS, A. G. Redução Sociológica. Rio de Janeiro: Tempo Brasileiro, 1965.

RAMOS, A. G. A nova ciência das organizações: uma reconceituação da riqueza das nações. 1. ed. Rio de Janeiro: Fundação Getúlio Vargas, 1981.

\section{RAMOS, A. G. Administração e contexto}

brasileiro. Rio de Janeiro: Fundação Getúlio Vargas, 1983.

SANTOS, B. D. S. Para uma sociologia das ausências e uma sociologia das emergências. Revista Crítica de Ciências Sociais, Coimbra, n. 63, p. 237-280, 2002 .

SANTOS, M. Técnica, espaço, tempo: globalização e meio técnico-científico-informacional.
5. ed. São Paulo: Editora da Universidade de São Paulo, 2008.

SCHUMACHER, E. F. O negócio é ser pequeno. Rio de Janeiro: Zahar, 1983.

SCOTT, W. R. Organizations: rational, natural, and open systems. 4. ed. Upper Saddle River: Prentice Hall, 1998.

SOUZA, M. M. P. D.; CARRIERI, A. D. P. Racionalidades no fazer artístico: estudando a perspectiva de um grupo de teatro. Revista de Administração de Empresas - RAE, São Paulo, v. 51, n. 4, p. 382-395, jul./ago. 2011.

SUMMERTON, J.; KAY, S.; HUTCHINS, M. Navigating rough waters: what kind of professional development do we need for managing and leading arts and cultural activity in England? A paper for the Fourth International Conference on Cultural Policy Research, Viena, Austria, July 2006.

TERRIEN, F. W.; MILLS, D. L. O efeito do tamanho sobre a estrutura interna das organizações. In: CAMPOS, E. (Org.). Sociologia da burocracia. Rio de Janeiro: Zahar, 1976. Cap. 3, p. 68-74.

THROSBY, D. Economics and culture. Cambridge: Cambridge University Press, 2003.

TOFFLER, A. A terceira onda. 23. ed. Rio de Janeiro: Record, 1998.

TONELLI, M. J. Sentidos do tempo e do tempo de trabalho na vida cotidiana. Organização \& Sociedade, Salvador, v. 15 , n. 45 , p. 207-217, abril/ junho 2008.

VIZEU, F. Contribuições da sociologia da dádiva aos estudos sobre organizações substantivas.

Organizaçãoe Sociedade, Salvador, v. 16, n. 50, p. 409-427, jul./set. 2009.

VOLBERDA, H. W. Building the flexible firm: how to remain competitive. New York: Oxford University Press, 1998.

WOODWARD, J. Organização industrial: teoria e prática. 1. ed. São Paulo: Atlas, 1977. 